\title{
Aluminium and Neuro-degeneration: Mechanism of Pathogenesis and Possible Strategies for Mitigation
}

\author{
Vikas Pankaj Bhargava', Aashish Kumar Netam', Rambir Singh² and Poonam Sharma ${ }^{1 *}$ \\ 'Department of Zoology, Indira Gandhi National Tribal University, Amarkantak - 484887, Madhya Pradesh, \\ India; vikas.luvs@gmail.com, aashishnetam@gmail.com,pnm245@yahoo.com \\ 2Department of Biomedical Sciences, Bundelkhand University, Jhansi - 284128, Uttar Pradesh, India; \\ sehrawat_r@yahoo.com
}

\begin{abstract}
One of the most abundant metal in our environment is aluminium (Al). Occupational exposure of humans to Al takes place during its extractions, processing and fabrications of articles of daily use. Al in drinking water and as well as its use in packaging \& storage of food is also a potential source of exposure. Acute exposure of higher concentration or chronic exposure of low concentration of Al leads to its aggregation in various parts of the body, resulting in system toxicity. Brain is highly susceptible to $\mathrm{Al}$ accumulation toxicity. In humans, exposure of $\mathrm{Al}$ is a risk factor for the starting of Alzheimer Disease. The adverse effect of Al exposure on nervous system results in memory loss, balance problems and impairment of coordination. High level of $\mathrm{Al}$ in brain increases lipid peroxidation and oxidative stress and reduces antioxidant enzymes level. It also causes aggregation of amyloid beta proteins and formation of Neurofibrillary Tangles (NFTs) of tau proteins which finally leads to death of neuronal cell and neurotoxicity. Metabolism and excretion of heavy metals including $\mathrm{Al}$ is very difficult and its leads to accumulation. The chelation therapy has been proposed where the organic molecules like EDTA, Chlorogenic acid and GSH binds with the heavy metals and facilitates for their excretion from body. However, non-specific binding of these chelators is another major safety concern. Medicinal plants and their phytochemicals with multiple mechanism of action have been proposed as a very good alternative for ameliorating heavy metal induced toxicity. In addition to mild chelating activities, the phytochemicals have antioxidant, anti-inflammatory, cytokine modulatory and other specific actions for proving holistic neuro-protection on heavy metal exposure.
\end{abstract}

Keywords: Aluminium, Beta-amyloid, Chelation, Medicinal Plants, Neurodegeneration, Tau protein, ROS

\section{Introduction}

Aluminium (Al) is one of the ample metals present on the Earth's crust and it is the third most common element. $\mathrm{Al}$ is found naturally in mineral rocks like bauxite (native aluminium hydroxide), cryolite (aluminium fluoride), micas and feldspars. Bauxite is the most predominant ore for commercial production of $\mathrm{Al}^{1}$. Bauxite mining industry is the major route of occupational exposure to
Al. Weathered rocks and mixed soil also constitute the major sources of $\mathrm{Al}$ in environment ${ }^{2}$. Exposure to bauxite dust containing high concentration of $\mathrm{Al}$ have been reported in mine workers with increased risk of mortality from cardiovascular and neurological disorders.

Occupational exposure may also take place from remelting, milling, grinding, welding and the production of $\mathrm{Al}$ articles $^{3}$. The mining activities in the bauxite rich areas lead to Al leakage in the soil, surface water

${ }^{*}$ Author for correspondence 
reservoirs and subsequently in water table. In surface water, concentration of $\mathrm{Al}$ is usually less than $0.1 \mathrm{mg} / \mathrm{L}$; but decrease in $\mathrm{pH}$ of the water reservoir enhances $\mathrm{Al}$ solubility, leading to increase in $\mathrm{Al}$ concentration ${ }^{2}$. This ultimately leads to the entry of $\mathrm{Al}$ in food chain and ultimately to humans, as we are the tertiary/ultimate consumers. The use of $\mathrm{Al}$ in every industry is increasing and it is rapidly replacing iron and other conventional metals. Al is a preferred packaging material for food items on account of being light and non-corrosive. Al containing materials are also usually present in processed foods as additives. These comprise firming agents in pickles, emulsifying agents in processed cheese, baking powder and many food colourings ${ }^{4}$. Some products of daily use like tea, toothpaste and infant formulas have been reported to contain $\mathrm{Al}$ (Figure 1) ${ }^{5,2}$. The concentration of $\mathrm{Al}$ in food items is variable ${ }^{5}$. In experimental animals, $\mathrm{Al}$ showed negative effects on the reproductive and nervous system that's why in 2007 the Provisional Tolerable Weekly Intake (PTWI) of Al was decreased from $7 \mathrm{mg} /$ $\mathrm{kg}$ body weight to $1 \mathrm{mg} / \mathrm{kg}$ body weight. However, the Joint FAO/WHO Expert Committee on Food Additives (JECFA) amended the PTWI to $2 \mathrm{mg} / \mathrm{kg}$ body weight in 2011, consequent of new bioavailability and toxicological data $^{2}$.

Medicinal uses of $\mathrm{Al}$ include $\mathrm{Al}$-oxide as an adjuvant in vaccines for enhanced immune activation. Buffered aspirin, antiperspirants and antacids usually contain $\mathrm{Al}^{4}$. $\mathrm{Al}$ has been widely in industry. The industrial application of $\mathrm{Al}$ involves the use of zeolite and bentonite in water purification, brewing, sugar refining and paper industries. $\mathrm{Al}$ was used with other components (magnesium, copper, silicon, manganese and zinc) for the manufacture of safety steel, electrical equipment, automobiles, packaging, construction materials, wiring, etc. $\mathrm{Al}$ powder is used in pigments, vehicles colours, fireworks, rocket propellers and explosives. $\mathrm{Al}_{2} \mathrm{O}_{3}$ is used in fire-obstructive fibres and abrasives $^{1}$. So, these broad uses make human exposure to $\mathrm{Al}$ almost inevitable.

It has been stated that $\mathrm{Al}$ aggregates in many mammalian tissues, e.g. the brain, liver, kidneys and bones, causing multiple system toxicity. Some reports have indicated that $\mathrm{Al}$ could deposit in the bone and significantly supress the growth and body weight in rats ${ }^{6}$. Surprisingly, Al have been reported to persist for longer time in humans as compared to rodents ${ }^{2}$. The shortterm exposure of $\mathrm{Al}$ rarely produces toxicity. During acute toxicity estimations, the oral $\mathrm{LD}_{50}$ for rats and mice

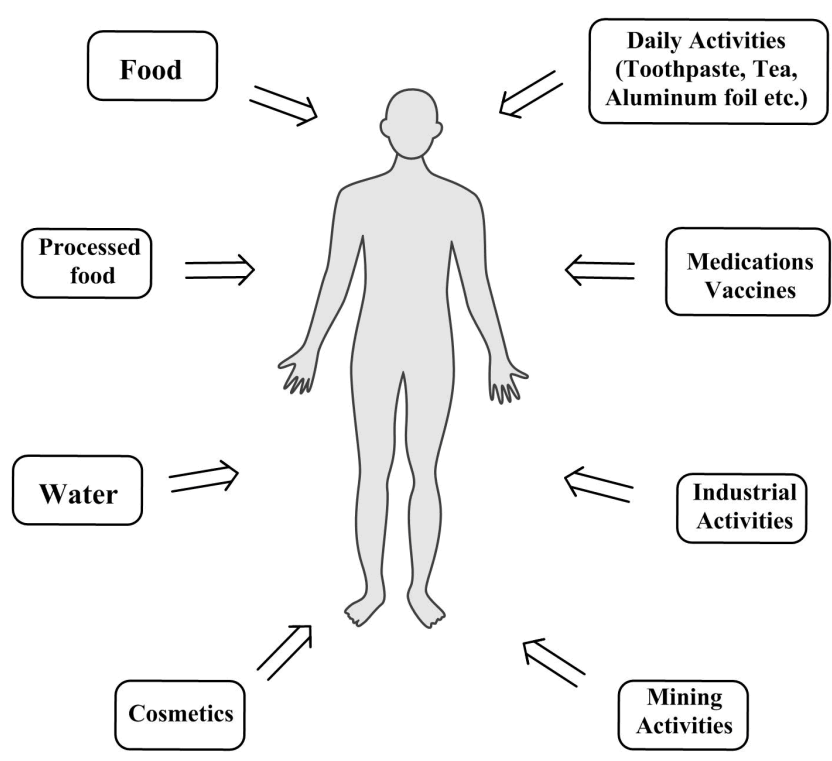

Figure 1. Some of the vital sources of bioavailable aluminium which shows harmful effects on human health

have been reported as 162 and $980 \mathrm{mg} / \mathrm{kg}$ body weight, respectively. In rats and mice, the high variability in $\mathrm{LD}_{50}$ is possibly because of various systemically available $\mathrm{Al}$ concentrations ${ }^{7}$. Acute toxicity of $\mathrm{Al}$ in humans is extremely rare.

Upon entering the body, 95 per cent of the ingested $\mathrm{Al}$ is eliminated by faecal matter, and the remaining 5 per cent circulates in the blood. The circulating $\mathrm{Al}$ can accumulate in different organs like liver, kidney, heart, testes, lung, brain, muscles bones etc. and causes toxicity ${ }^{8}$. Rising in the liver enzymes such as AST, ALT and ALP, was observed on Al exposure indicating liver damage and dysfunction. Enhance in ALP activity can be attributed to serious loss to cell membranes or enhanced permeability of plasma membrane of liver'. The reproductive toxicity of $\mathrm{Al}$ in animal's models have been studies in details. $\mathrm{Al}$ exposure is responsible for impaired or total failure of spermatogenesis and decreased sperm count. It is documented that in hypothalamus cells, Al can block sensitive calcium channel voltages and decrease the secretion of gonadotrophin-releasing hormone ( $\mathrm{GnRH}$ ) which leads to a decrease in pituitary follicle stimulating hormone (FSH) and luteinizing hormone (LH). Reduced FSH and LH levels disturbed the spermatogenesis process and the release of testosterone by the leydig cells ${ }^{10}$. Al has also been reported to accumulate in the parathyroid glands. The parathyroid glands concentrate $\mathrm{Al}$ above 
levels in surrounding tissues. Al changes the level of parathyroid hormone by decreasing its synthesis ${ }^{8}$. Upon entry in human body, through nasal route, $\mathrm{Al}$ shows Asthma-like symptoms known as "potroom asthma" with impaired lungs function. It also causes pulmonary fibrosis. Excessive amount of $\mathrm{Al}$ interferes with the bone remodelling by reducing bone formation by impairment of osteoblastic activity and causes osteomalacia. It also causes muscles pain, anaemia and impaired renal function etc ${ }^{11}$.

\section{Routes of Exposure}

Oral, respiratory and subcutaneous modes have been identified as the major routes of entry of $\mathrm{Al}$ in human body ${ }^{12}$. Studies on humans and animals have estimated oral bioavailability of $\mathrm{Al}$ in drinking water $(0.3 \%)$ and food and beverages $(0.1 \%)$. Al absorption from oral ingestion is usually low and about $95 \%$ is excreted via faeces. Few compounds which are present in our diet like lactate, citrate, gluconate, ascorbate, tartrate, succinate, oxalate and malate can enhance $\mathrm{Al}$ absorption. It has been reported that $\mathrm{Al}$ absorption from gut may boost because of decreased plasma levels of magnesium and iron as well as increased vitamin $\mathrm{D}$. Absorption of $\mathrm{Al}$ has been suggested to be the first uptake by mucosal cells followed by gradually release into the blood. There are evidences in support for $\mathrm{Al}$ absorption through active transport and paracellular diffusion in intestinal cells. The active transport mechanism suggests role for transferrin (Tf). Tf is the main iron transport protein in vertebrates. In vitro experiment with separated rat intestine, addition of Tf to the perfusion medium increased release of $\mathrm{Al}$ from mucosal cells into blood (Figure 2$)^{13}$.



Figure 2. Location and mechanism of absorbance of ingested aluminium. 
Nasal route is another major route of occupational exposure to $\mathrm{Al}$. The workers in bauxite mines and $\mathrm{Al}$ industry are largely exposed to Al dust and vapours. When $\mathrm{Al}$ enters the nasal cavity, either it is directed towards the olfactory epithelium or the respiratory epithelium and neuronal supply to the nasal cavity. Al affecting the respiratory epithelium will soften into the mucus layers lining the epithelium or it will be transported by cilia towards the back of the throat for muco-ciliary clearance. Afterwards, $\mathrm{Al}$ will move to the gut while $\mathrm{Al}$ permeates the mucus layers will stay within the respiratory epithelium and shall be absorbed in systemic circulation. The cilia, which present in olfactory epithelium, are nonmotile. $\mathrm{Al}$ exposing this surface will get larger surface area for absorption and disintegration into the mucus layer lining the epithelium. The olfactory epithelium is virtually constant uninterrupted with the olfactory bulb and olfactory nerve. So, from this source represents a direct uptake route of $\mathrm{Al}$ into the brain (Figure 3$)^{14}$.

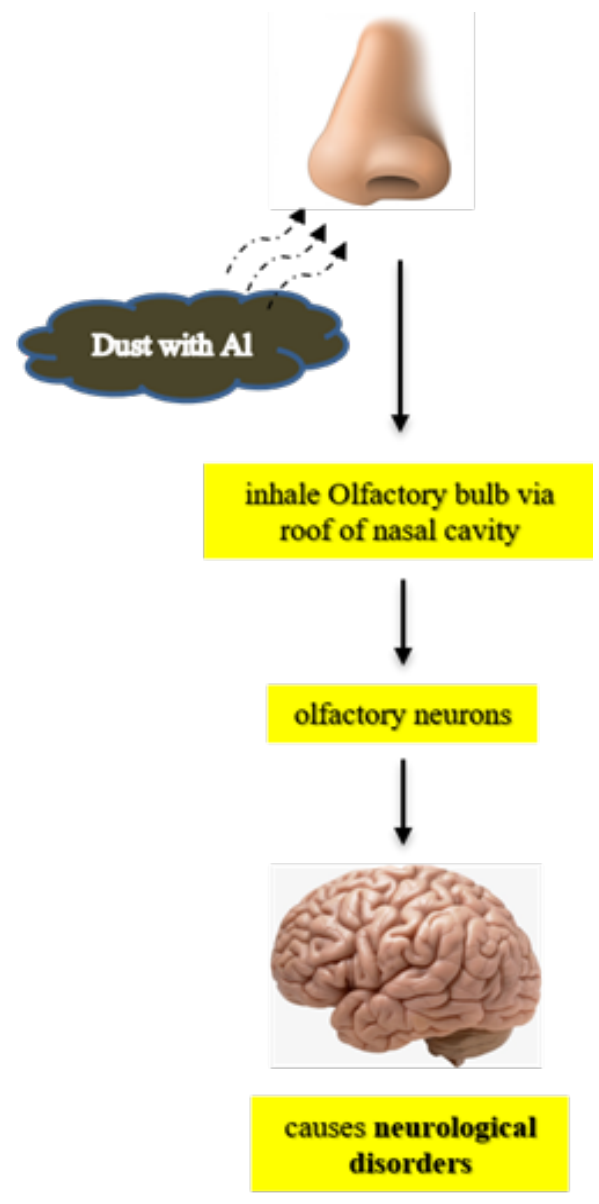

Figure 3. Intranasal absorption of aluminium.
On absorption, almost one-half of the $\mathrm{Al}$ deposits in the skeleton system (approx 5-10 mg/kg) and nearly one-fourth deposits in the lungs. In humans, $\mathrm{Al}$ has been detected in skin, lymph nodes, lower gastrointestinal tract, parathyroid glands, adrenals and soft tissues. In rats, increased level of $\mathrm{Al}$ were found in liver, spleen, kidneys and bone compared to muscle, lungs, heart and brain ${ }^{2}$.

\subsection{Exposure of Al to Brain}

Al from blood has been reported to cross the bloodbrain barrier (BBB) via Transferrin-Receptor Mediated Endocytosis (TfR-ME) and enter in brain. Tf enhanced in vitro uptake of Al into oligodendroglia and neuroblastoma cells as $\mathrm{Tf}$ binds $\mathrm{Al}^{3+}$ with high affinity. It has also been reported that in blood, $\mathrm{Al}$ binds to citrate to generate $\mathrm{Al}$ citrate. Al citrate can cross $\mathrm{BBB}$ and facilitate the entry of $\mathrm{Al}$ in brain, independent of TfR-ME pathway ${ }^{13}$. By inhalation route entry, $\mathrm{Al}$ may directly enter the brain from nose via olfactory neurones, that move from the roof of the nasal cavity to the olfactory bulb. Inhalation of $\mathrm{Al}$ chlorohydrate to rats showed $\mathrm{Al}$ in the brain stem nuclei, proposing olfactory nerve uptake and distribution of trans-synaptic Al.

\section{Mechanism of Al Induced Neurotoxicity in Animals including Human}

The morphological changes in brain during neurodegenerative diseases vary from people undergoing natural aging. The natural brain aging has been associated with loss in temporal organization and characterised by a decreased ability to retort to worry, successive relapse of mental and physical performance, along with reduced metabolic rate, immunity and hormonal activity ${ }^{15}$. In neurodegenerative diseases, Al has been suggested as a significant contributing element ${ }^{16}$. Various animal studies have shown neurobehavioral, neuropathological, neurochemical and neurophysical changes on exposure of $\mathrm{Al}$, resulting in impaired learning and memory ${ }^{12}$ Al has been recognised as a neurotoxin, causing speech disturbances, memory loss, jerking movements, tremors, dyspraxia, impaired muscular coordination and paralysis. In the brain, exposure to $\mathrm{Al}$ caused neuronal degeneration affecting especially the 
cholinergic cells. Development encephalopathy with profound cognitive deficits, in-coordination, tremor and spinocerebellar degeneration have been reported in subjects working in $\mathrm{Al}$ industry ${ }^{17}$.

We have reviewed some of the possible mechanisms of $\mathrm{Al}$ induced neuro-degeneration.

\subsection{Role of Reactive Oxygen Species (ROS)}

ROS are at the centre stage of certain pathological processes for inducing neuro-degeneration. ROS are naturally originated in biological system as by-product of cellular respiration and are also involved in certain vital cellular activities like pathogen defence, inflammation and stressor responses ${ }^{18}$. The excess ROS are generally inactivated by endogenous antioxidants, to protect cell for any kind of oxidative injury. Enhanced production of ROS under any xenobiotic exposure adversely affects cell survival and function. The brain is vulnerable to ROS because of its highly lipophilic nature (which promotes xenobiotic accumulation), high oxygen consumption rate and weak antioxidant defence ${ }^{16}$. Although ROS might not be directly involved in inducing neurodegenerative diseases, they may intensify progression of illness by oxidative injury. The pathological processes of many neurodegenerative disorders are related to the build-up of misfolded proteins. Inflammatory response and oxidative stress can later be triggered by the accumulation of these altered proteins ${ }^{18}$.

Excessive production of ROS is believed to play a vital role in the accumulation and deposition of beta-amyloid $(\mathrm{A} \beta)$ proteins during neurodegenerative diseases. ROS possibly play a part in mediating JNK/stress-activated kinase pathways. Beta-amyloid plaques are formed due to accumulation of beta-amyloid proteins. The beta-amyloid plaques enhances calcium ions $\left(\mathrm{Ca}^{2+}\right)$ accumulate in endoplasmic reticulum (ER), leading to increase in cytosolic calcium ions concentration. The enhanced cytosolic calcium leads to depletion of endogenous Glutathione (GSH) levels and over accumulation of ROS within the cells. These processes are involved in the hyper phosphorylation of tau proteins and betaamyloid induced necrobiosis in brain ${ }^{19}$. Beta-amyloid proteins have also been reported to begin the formation of free radical through the NADPH oxidase activation. It also augments the calcineurin activity, that successively triggers death promoter associated with $\mathrm{Bcl}-2$, resulting in mitochondria releases cytochrome $\mathrm{c}$ with induction of
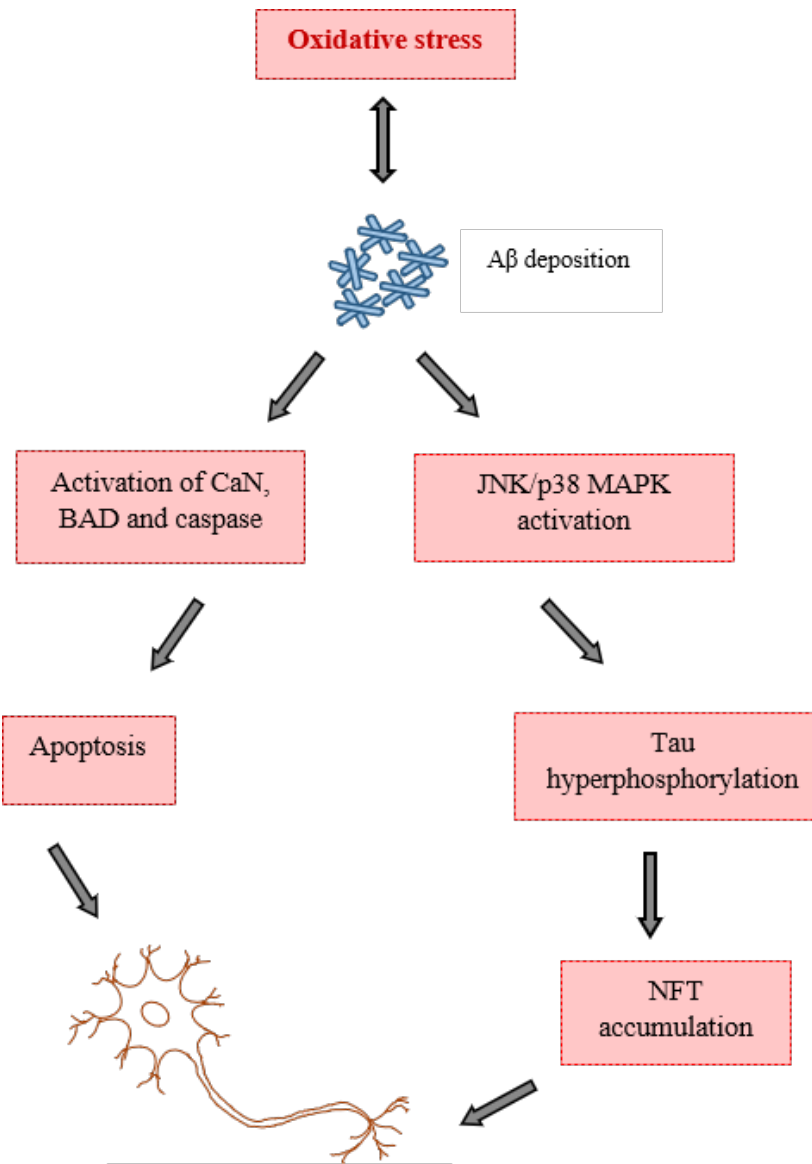

NFT accumulation Neurodegeneration

Neurological diseases

$\mathrm{CaN}=$ Calcineurin

$\mathrm{BAD}=\mathrm{Bcl}-2$ related death promoter

$\mathrm{JNK}=\mathrm{c}$-Jun $\mathrm{N}$-terminal kinase

$\mathrm{MAPK}=$ mitogen-activated protein kinase

Figure 4. Contribution of oxidative stress in the progression of neurological diseases.

neuronal apoptosis. Thus, ROS and oxidative stress are at the center stage of brain injury in neurodegenerative diseases (Figure 4$)^{16}$. Inflammation, aging, environmental factors (chemicals, pollutants and radiation) and a few nutritious factors (redox-active metals) can induce extra oxidative stress resulting in enhanced beta-amyloid production $^{18}$.

$\mathrm{Al}$ and other heavy metals have a tendency of accumulation in the fatty tissues, brain, inducing formation of oxygen and other free radicals. ROS and 
free radical $\mathrm{H}_{2} \mathrm{O}_{2}$ together induces oxidative stress. All biological macromolecules, including proteins, lipids, carbohydrates and nucleic acids, interact with ROS. Enhanced lipid peroxidation (LPO) is a primary result of oxidative stress. $\mathrm{Al}$ has been suggested to promote ironinduced LPO, noniron-induced LPO, noniron-mediated $\mathrm{NADH}$ oxidation and noniron-mediated hydroxyl radical $\left(\mathrm{HO}^{*}\right)$ oxidation in both in vivo and in vitro ${ }^{20}$. Increased ROS level and oxidative damage in brain causes mitochondrial dysfunction including inflammation and it increases neuronal death, which is associated with many neurodegenerative disorders ${ }^{21}$.

\subsection{Role of Tumor Necrosis Factor-alpha (TNF- $\alpha$ )}

Tumor necrosis factor alpha (TNF- $\alpha$ ) is an apparent inducer of oxidative stress in the brain. The cytokine Interferon- $\gamma$ (IFN- $\gamma)$ is released by infiltrated $\mathrm{T}$ cells. In microglia, IFN- $\gamma$ activates production of TNF- $\alpha$ by the help of IFN- $\gamma$ receptor. In microglia, TNF- $\alpha$ stimulates its own discharge via TNFR1 signaling, after that it also stimulates the release of glutamate from hemichannels of gap junctions which acts on microglial metabotropic glutamate receptors to induce extra release of TNF- $\alpha$.

In astrocytes, TNF- $\alpha$ activates TNFR1 to stimulate glutamate exocytosis, raising level of extracellular glutamate. In neurons, TNF- $\alpha$, through TNFR1, quickly enhances the excitatory synaptic potency by motivating enhanced calcium permeable-AMPA ( $\alpha$-amino-3hydroxy-5-methyl-4-isoxazolepropionic acid) receptors and/or NMDA receptors and declines the surface expression of inhibitory $\mathrm{GABA}_{\mathrm{A}}$ receptors. The extreme calcium input to neurons motivates death of neurons and produces in large amount of ROS that interrupt transport of glutamate in neighbouring astrocytes (Figure 5). The dying neurons retain an active state of microglia that regulates their enhanced production and release of TNF- $\alpha$. Activated microglia release TNF- $\alpha$ these mechanistic links among excitotoxicity and neuroinflammation may be thought-about as a crosstalk between microglia and astrocytes and microglia and neurons $\mathrm{s}^{22}$.

In the healthy CNS, it has a physiological role in regulating synaptic transmission of nerve impulse and plasticity by harmonizing ionotropic glutamate receptors trafficking. In response to an excitotoxic insult, ROS produced within neurons can pass through the plasma membrane and disrupt glutamate transport in adjacent astrocytes. Facts suggest that transporters of glutamate are sensitive to the action of reactive oxygen and nitrogen species that, within minutes, restrict glutamate uptake. Though it has been documented that high levels of TNF- $\alpha$ have an inhibitory impact on transporters of glutamate, leading to enhanced glutamate concentration in CNS parenchyma, even minor enhances in TNF- $\alpha$ induced by calcium ions permeable-AMPA and/or NMDA receptors trafficking become toxic for neurons. Activation of microglia and TNF- $\alpha$ upregulation has been commonly observed in neurological diseases ${ }^{22}$.

In another mechanism, TNF- $\alpha$ induces excitotoxicity by enhancing microglial glutamate level. In primary microglia, group 2 metabotropic glutamate receptors (mGluR2) stimulation induced release of TNF- $\alpha$. Two microglial autocrine pathways may be involved in excite-toxicity: TNF- $\alpha$ promotes production and release of microglial TNF- $\alpha$ via TNFR1 signaling pathway and second, TNF- $\alpha$ induces release of glutamate which in turn activate microglial mGluR2 for induction of more production of TNF- $\alpha$. In astroglia, TNF- $\alpha$ activates TNFR1, triggering a series of events leading to prostaglandin generation E2 which in turn raises intracellular calcium followed by glutamate exocytosis. The exorbitant concentration of glutamate activates neuron with increase in intracellular $\mathrm{Ca}^{2+}$, leading to oxidative stress and accelerated neuronal death (Figure 5) $^{23}$.

AMPA-type glutamate receptors (AMPARs) are ligand gated channels responsible for rapid excitatory synaptic transmission in the neurons. These receptors are tetramers assembled from glutamate receptor (GluR) $1,2,3$ and 4 subunits around an aqueous pore in the membrane. TNF- $\alpha$ has a significant role in AMPARs regulation trafficked being a vital component of the homeostatic regulatory system monitoring synaptic plasticity. TNF- $\alpha$ decreases AMPAR-mediated calcium admission in cultured motoneurons by augmenting cell surface expression of the GluR2 subunit ${ }^{24}$.

Though astrocytes and neurons are capable to generate TNF- $\alpha$. During neuroinflammation, it is supposed that microglia are the main source of TNF- $\alpha$ cytokine. In microglia, the cytokine IFN- $\gamma$ is a strong inducer of TNF- $\alpha$ gene expression. The various inflammatory stimuli which stimulate microglia during neuroinflammation trigger various signalling pathways including JNK, p38 MAPK, 


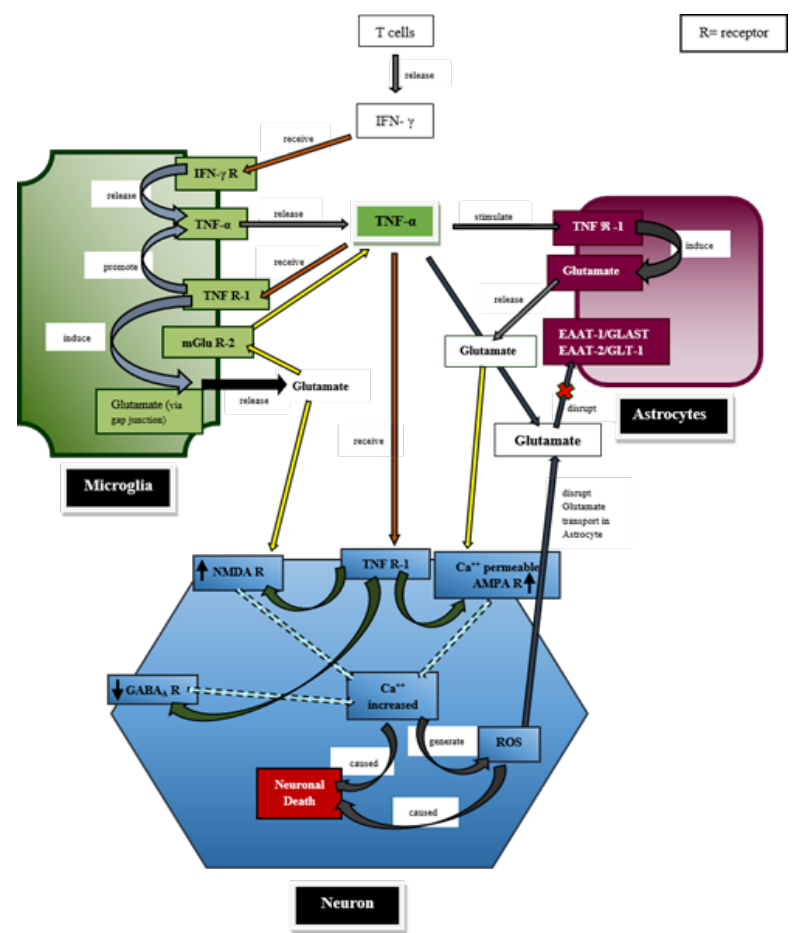

Figure 5. Cytokine TNF- $a$ connects the neuroinflammatory respond to glutamate-mediated toxicity.

ERK1/2 and NF- $\kappa B^{25}$. IFN- $\gamma$ is generated by $T$ cells but not in considerable amounts through any CNS resident cells, including microglia. Role of the infiltrated $\mathrm{T}$ cells in the CNS is contentious, because both $\mathrm{CD} 4^{+}$and $\mathrm{CD}^{+}$ $\mathrm{T}$ cells can have injurious or protective impacts, during the neuroinflammatory procedure, these infiltrated cells release the cytokine IFN- $\gamma$ which, through the MEK/ERK signaling pathway, motivate in microglia an increased de novo production and release of TNF- $\alpha$. Microglia may be activated to TNF- $\alpha$ release at early asymptomatic disease periods through sensing the earliest neuronal stress and afterwards, infiltrated $\mathrm{T}$ cells discharging IFN- $\gamma$ would retain microglia in an active situation ${ }^{26}$.

\subsection{Role of Beta Amyloid and Tau Protein}

Abnormalities in beta-amyloid and/or tau protein has been largely allied with neurological disorders. Overproduction of beta-amyloid proteins and hyper phosphorylated tau protein have been observed in synaptic connections and neurons in the hippocampus and cerebral cortex of patients suffering from neurological disorders. Excess production and deposition of betaamyloid lead to peroxidation of lipids, cell functions disturbance, inflammation, apoptosis and neurofibrillary tangle (NFT) formation. The hyper phosphorylation of tau protein leads to the creation and accumulation of NFT in the hippocampus leading to neuronal death. It has been reported that inflammation, oxidative stress, metabolic disturbances, disintegration of calcium homeostasis and the deposition of unfolded/mis-folded proteins accelerates neuronal cell death in patients with neurological disorders ${ }^{27}$.

The faulty processing of Amyloid Precursor Protein (APP) (771 amino acids) leads to the generation of beta-amyloid protein. In first step, APP is cleaved by $\beta$-secretase and then by second enzyme, $\gamma$-secretase to generate beta-amyloid, with length of 38,40 or 42 amino acids. Beta-amyloid is chemically stickier than the other lengths due to the length of 42 amino acids, so it leads to clumps and plaque formation. The groups of betaamyloid proteins stick together are known as amyloid plaques. In the brain, the amyloid plaques accelerate the neuronal cells death and leads to neurological disorders. Beta-amyloid plaques enhance production of ROS, dysfunction of mitochondria and apoptosis as well as the down regulation of antioxidant genes in neuronal cells, leading to dysfunction of neuronal cell and deteriorated neurodegenerative symptoms. The beta-amyloid plaques also harm neuronal cells by inducing inflammatory reaction. The level of interleukin-1 (IL-1), interleukin-6 (IL-6) and TNF- $\alpha$, have been enhanced in neuronal cells on interaction with beta-amyloid plaques ${ }^{27}$.

Tau proteins are the microtubule-associated proteins. These proteins play a very essential role in the pathogenesis of neurodegenerative diseases. In humans, they are largely present in neurons, though non-neuronal cells also found in low quantity but easily detectable. The main function of the tau protein is to harmonize the stability of axonal microtubules and these proteins are primarily active in the distal portions of axons. These proteins are essential for the dynamics of axonal growth cones and effective axonal transport. Tau proteins supports kinesin and dynein-based anterograde and retrograde transport; thus, they enable the cargo packages movement towards and from the perykaryon to the axon/dendrites. If the axonal transport is affected, Synapses are affected ${ }^{28}$.

Phosphorylation of serine/threonineproline residues control the normal biological functions of tau proteins. Phosphorylation is regulated during growth, fetal brain tau protein being more phosphorylated than the adult brain. It has been reported that during neurodegenerative diseases, accumulates composed of glycated and highly 
phosphorylated tau neurofibrillary tangles (NFTs) are formed. It has been reported that phosphorylation level of tau is 3 to 4 folds greater in the brain of patients with neurodegenerative disease as compared to normal human brains ${ }^{28}$. According to histopathological point of view, mutations in tau protein may cause the formation of various forms of insoluble aggregates of protein, including NFTs. The irregular accumulation of transformed tau

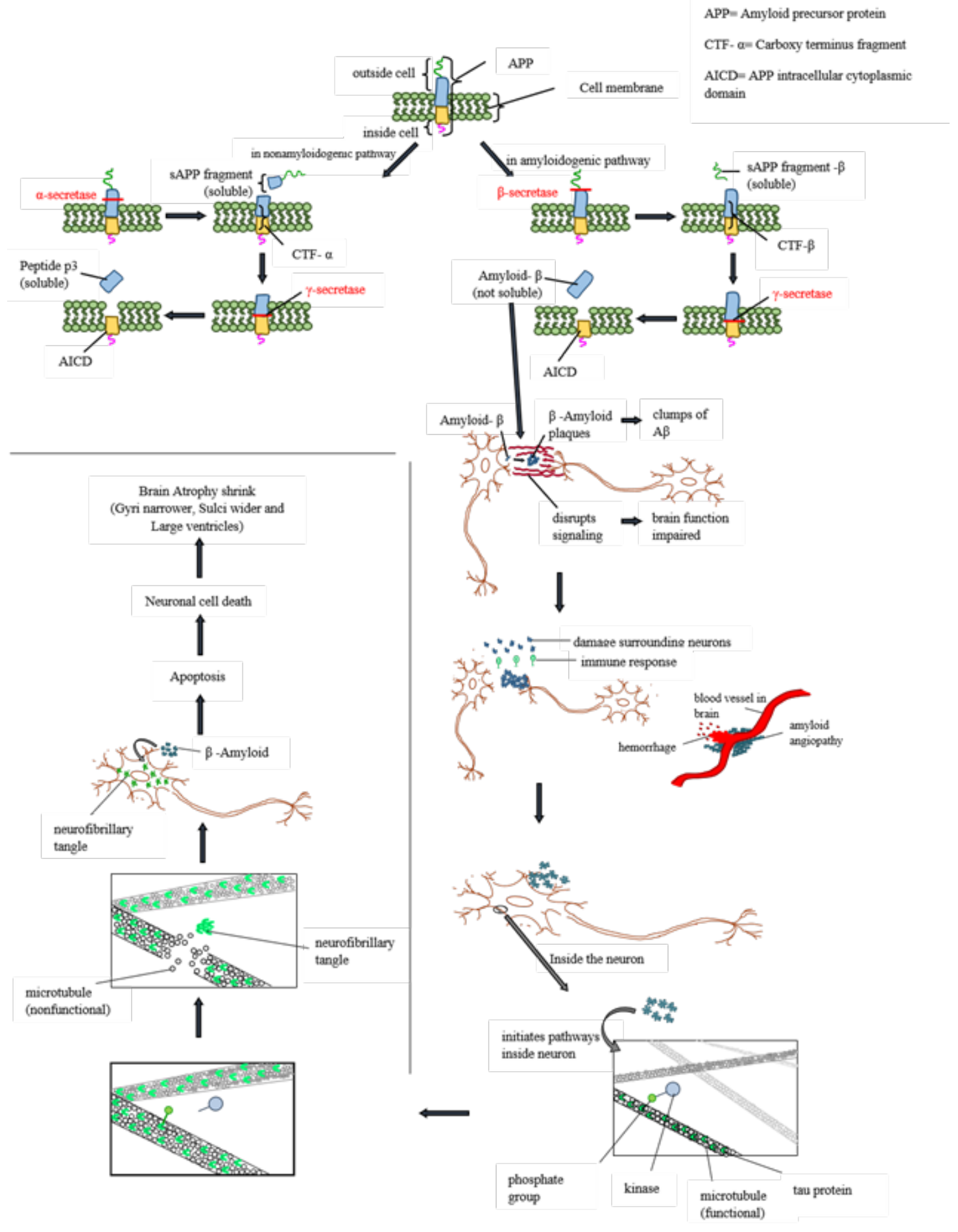

Figure 6. APP [Amyloid Precursor Protein] Pathway in neurotoxicity. 
proteins in the neurons in many neurodegenerative diseases (Figure 6). It is known as "tauopathies"29.

\section{Strategies of Prevention and Treatment}

It is well documented that $\mathrm{Al}$ in excessive amounts is toxic to animals including humans. Once inside the biological system, its excretion from body is major challenge. The aggregates of $\mathrm{Al}$ are too small to elicit any immune response. Since $\mathrm{Al}$ is having very low tendency of making complex with bio-molecules, it may easily evade the xenobiotic biotransformation system of animals. Various approaches have been proposed for mitigation of $\mathrm{Al}$ toxicity.

\subsection{Chelation Therapy in Management of Al Toxicity}

Chelation is a procedure using chelating agents to discard toxic metals from the body. Chelation therapy uses ligating molecules that bind and quenches metal. The ligands promotes bio-transformation of the conjugate and helps in excretion of the toxic metals from biological systems ${ }^{30}$. Laboratory animal trials and clinical experience indicate that the administration of an effective chelating agent can improve acute or chronic metal toxicity ${ }^{31}$. A well-known chelating agent used in the treatment of heavy metal toxicity is Ethylenediaminetetraacetic Acid (EDTA). Fulgenzi \& Ferrero have proposed the mechanism underlying the impact of EDTA chelation therapy against neurotoxicity. Xenobiotics (organophosphorus pesticides, toxic metals, drugs, air pollutants) can harm glial cells and/or neurons. Activated glial cells and endothelium produces ROS and proinflammatory cytokines (TNF- $\alpha$, IL-1), which harm neurons (Figure 7). EDTA has been proposed to offer: (1) Protection against endothelial activation; (2) removal of toxic metals; (3) possible anti-inflammatory functions; (4) antioxidant activity (reducing ROS levels) $^{32}$. Chlorogenic acid, a chelating scavenger of $\mathrm{Al}$ in vitro, have been reported to prevent $\mathrm{Al}$ absorption and also reduce $\mathrm{Al}$ induced oxidative stress ${ }^{33}$. GSH has also been reported to reduces the concentration of $\mathrm{Al}$ in the body via chelation ${ }^{34}$.

Some study revealed that coriander act as a chelating agent, it can remove heavy metals from CNS. It is beneficial against lead and mercury toxicity. Garlic also shows chelating property. It has long been reported that sulfhydryl-containing compounds are capable to chelat metals. The sulfur-containing amino acids cysteine and methionine, $\mathrm{N}$-acetylcysteine an acetylated analog of cysteine, the methionine metabolite S-adenosylmethionine and $a$-lipoic acid, all contribute to the chelation and defecation of metals from the human body ${ }^{35}$. Another study reported that Rosmarinus officinalis shows chelating effect against $\mathrm{Fe}^{2+}$. Another mechanism of curcumin in decreasing $\mathrm{A} \beta$ accumulation or oxidative neurotoxicity is by metal chelation ${ }^{36}$. Al toxicity has also been treated using deferasirox and deferiprone as chelating agent ${ }^{30}$. Although, chelation is the only possible therapy to ameliorate heavy metal poisoning, it must be used in a very judicious way. The chelators may also bind to essential minerals such as iron and calcium leading to their deficiency. The reported chelation therapy's side effects include low blood calcium, dehydration, increased enzymes, harm to kidneys as would be detected in liver function tests, lowered levels of dietary elements and allergic reactions ${ }^{35}$.

\subsection{Medicinal Plants in Management of Al}

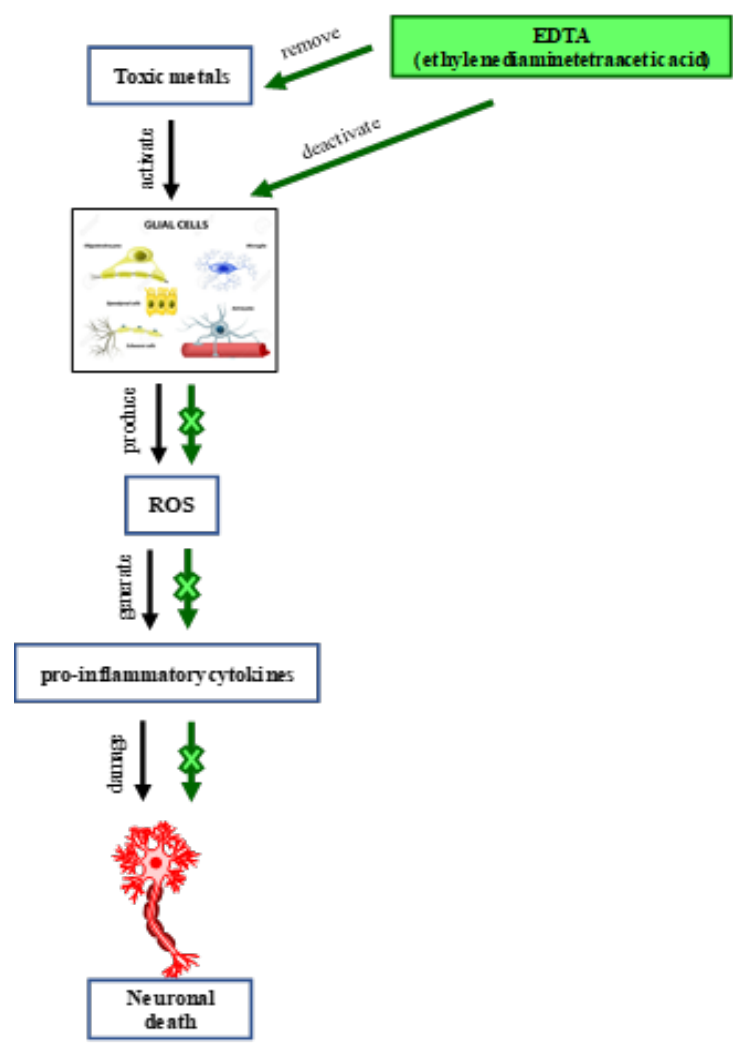

Figure 7. Proposed mechanisms sharing the impact of ethylenediaminetetraacetic acid chelation therapy against neurotoxicity ${ }^{32}$ 


\section{Induced Neurotoxicity}

Medicinal plant based natural products may have a significant role to play in the improvement of heavy metals including toxicity of $\mathrm{Al}$ in humans and animals. The phytochemicals may be effective chelators of heavy metals and may also show protective effect by exhibiting antioxidant and anti-inflammatory activities. The plant products may also exhibit neuro-protective effect by modulating the brain functionalities by multiple mechanisms.

Ethanolic extract of Jasonia candicans \& Jasonia montana $(150 \mathrm{mg} / \mathrm{kg}$ body weight daily for 6 weeks) worked as detoxification agent and showed anti-amyloidogenic, anti-inflammatory, antioxidant and anti-cholinesterase activities against $\mathrm{Al}$ induced neurotoxicity in rats. J. montana showed free radicals scavenging and chelating activity against metal ions ${ }^{9,37}$.

Withania somnifera (Ashwagandha) shows antioxidant and free radical scavenging activity. $W$. somnifera aqueous extract also to increased cholinergic activity ${ }^{9}$. Chitra and Ramaswamy demonstrated that Ashwagandha was effective against neuroinflammation in rat and human at a dose of $140 \mathrm{mg} / \mathrm{kg}$ body weight and $500 \mathrm{mg} /$ day respectively ${ }^{38}$. Rosmarinic acid, the constituents of Rosmarinus officinalis, has been documented as potent antioxidant that protects against damage caused by free radicals. It also showed anti-inflammatory, anti-amyloid, ROS scavenging and antiacetylcholinesterase (anti-AChE) activities and inhibits the TNF- $\alpha$-induced signaling pathways ${ }^{36}$. Ethanolic extract of Salvia officinalis leaves showed anti-inflammatory and anti-apoptotic activities. It decreased ROS production, Malondialdehyde (MDA) levels and increased Glutathione Peroxidase (GPx) activity and GSH levels ${ }^{39}$.

Ethanolic extract of Scutellaria baicalensis decreased the level of NO, nitric oxide synthase (iNOS), prostaglandin E2 and cyclooxygenase-2 (COX-2). It also inhibits $\mathrm{A} \beta$ production, prevents tau phosphorylation and it also acts as an antagonist of AMPA and NMDA receptors, improves neurocognition ${ }^{36}$.

Alcoholic extract of Hypericum perforatum showed antidepressant, antioxidant, anti-inflammatory, antibacterial properties. It decreased lipid peroxidation and enhanced cognitive function and memory. Hyperforin, a phloroglucinol derivative from $H$. perforatum showed decrease in $\mathrm{Al}$ induced beta-amyloid production and aggregation, reduction in expressions of APP and inhibition of tau protein hyper phosphorylation.
It also showed activation of astrogliosis and microglia in vitro and in transgenic rodent models ${ }^{40}$. Mohebbati et al. reported that $300 \mathrm{mg} / \mathrm{kg}$ body weight dose of H.perforatum was effective against neurotoxicity in mice. Lavandula angustifolia showed inhibition of cholinesterase. Opuntia ficus-indica showed antioxidative property, inhibited lipid peroxidation and reduced neuronal damage ${ }^{39}$. Quercetin, isolated from this plant showed neuroprotective action against chemically induced neurotoxicity ${ }^{41}$. It has been documented that the phytochemical Indicaxanthin from this plant crosses $\mathrm{BBB}$ and exhibits a neuroprotective effect $^{42}$. Ficus religiosa fruits contain high amount of serotonin (5-hydroxytryptamine or 5-HT) and amino acids. 5-HT acts as neurotransmitter and regulate neurobehavioral processes including cognitive functions. The plant showed AChE inhibitory activity with $\mathrm{ED}_{50}$ of $50-100 \mathrm{mg} / \mathrm{kg}$ body weight in mice ${ }^{39}$.

Methanolic extract of Curculigo orchioides promotes restoration of activities of superoxide dismutase (SOD) and antioxidant enzymes catalase (CAT), enhanced GSH level and decreased MDA levels. Ethanolic extract of Pongamia pinnata decreased LPO and increased level of GSH, SOD and CAT. Extract of Angelica sinensis scavenged intracellular ROS and modulated MDA and GSH contents in beta-amyloid induced neurotoxicity. Juglans regia being rich in polyunsaturated fatty acids and vitamin E, improved learning and memory processes ${ }^{39}$.

Administration of extract of Crocus sativus and honey syrup reduced $\mathrm{AlCl}_{3}$-induced neurotoxicity in mice. Nigella sativa and Ferula assafoetida resin reduced the AChE activity. Oil of Thymus vulgaris can directly react with free radicals and prevent LPO. An oxygenated monoterpene isolated from T. vulgaris and Zataria multiflora acts on beta-amyloid, which is responsible for neurodegenerative diseases. Curcumin from Curcuma longa showed anti-inflammatory activity, inhibited ROS production, brain oxidative damage, apoptosis, cognitive deficits in cell culture and experimental animal models. It also decreased IL-1 $\beta$, IL-6, TNF- $\alpha$, plaque deposition and suppressing inflammatory damage in $\mathrm{A} \beta$ induced neurotoxicity. Water soluble extract of Curcuma longa has been reported to increase the levels of norepinephrine, dopamine, 5-HT in CNS. It restores decreased levels of GSH and increases SOD levels ${ }^{43}$.

Combined administration of extracts of Triphala and Allium sativum reduced $\mathrm{Al}$ concentration in albino mice. A. sativum has also been reported to reduce mitochondrial injury ${ }^{9}$. Extract of Ginkgo biloba leaves increased oxygen 
supply to brain, inhibited ROS generation and eliminated other free radicals also ${ }^{44}$. Panax ginseng root's aqueous extract reduced the ROS overproduction and also shows anti-inflammatory activity. It upregulated the activities of CAT, SOD, increased GSH and reduced level of TNF$\alpha, \mathrm{MDA}$ and $\mathrm{A} \beta$ in the brain. It also inhibits the $\mathrm{AChE}$ activity. Polygala paniculata showed anti-glutamatergic effect in neurodegenerative disorders ${ }^{39}$.

Some isolated phytochemicals, mainly phenols and flavonoids have shown good antioxidant and metal ion chelator activities. The Phenolic hydroxyl groups are good hydrogen donors. In a termination reaction, they can bind to reactive nitrogen and reactive oxygen species which can break the cycle of new radicals generation. The ability of phenolic compounds to chelate metal ions involved in the creation of free radicals is also due to their antioxidant power. However, phenolics can act as pro-oxidants by chelating metals in a manner that they maintains or enhances their catalytic activity or by decreasing metals. Thereby, enhancing their ability to form free radicals ${ }^{45}$.

Flavonoids are another potential antioxidants and metal chelators from plants. Antioxidant properties of flavonoids are due to hydroxyl group. The greater number of free hydroxyl groups generally correlates to a higher scavenging effect. Flavonoids are capable of chelating metal ions, stopping them from forming free radicals and shielding cells from oxidative stress. The entire antioxidant impact of flavonoids seem to be a combination of direct reaction with free radicals and chelating properties responsible for the production of ROS. Such compounds can chelate several metal ions and form various types of complexes. Metal-flavonoid complexes are better than free flavonoids in terms of free radical scavenging property. Flavonoid complexes have an effect on deficiency of bioavailability of toxic metals. It has been reported that Quercetin complex with $\mathrm{Al}(\mathrm{III})$ and reduces its absorption from $\operatorname{diet}^{46}$.

Gastrodin, isolated from Gastrodia elata, reduced free radical generation and inhibited the level of neurotoxic proinflammatory mediators and cytokines inclusive of COX-2, iNOS, IL- $1 \beta$ and TNF- $\alpha$. Resveratrol from Polygonum cuspidatum improved mitochondrial function and also inhibited formation of $\mathrm{A} \beta$. Baicalein from Scutellaria baicalensis inhibited the production and accumulation of ROS and mitigated astroglial response. It also suppressed apoptosis and promotes mitochondrial active respiration. Pinocembrin from Sparattosperma leucanthum, showed anti-inflammatory activity and inhibited $\mathrm{A} \beta$-induced neurotoxicity. Puerarin obtained from Pueraria lobate suppressed $\mathrm{A} \beta$ induced neuronal death. Galantamine isolated from Galanthus woronowii and Rivastigmine obtained from Physostigma venenosum inhibited AChE activity. Tenuigenin acquired from Polygala tenuifolia dried roots decreased secretion of NO, IL-6, IL- $1 \beta$ and TNF- $\alpha$. Zederone epoxide from Chloranthus henryi, showed anti-inflammatory effect. It suppresses the activity of COX-2, iNOS, manufacturing of IL- $1 \beta$, TNF- $\alpha$ and NO. Atractylenolide-I is obtained from Atractylodes macrocephala rhizomes. It decreases microglial activation and prevents $\mathrm{A} \beta^{(25-35)}$ induced toxicity. Paeoniflorin obtained from Paeoniae alba Radix and it shows anti-neuroinflammatory effects ${ }^{36}$.

\section{Conclusion}

Aluminium is widely used element in daily life. The anthropogenic activities related with extraction and processing of $\mathrm{Al}$ for industrial and domestic use lead to occupational exposure. Al contamination in water and food resources from the extractions and other industrial activities resulted in its entry in food chains and food webs, exposing animals including humans.

Brain is susceptible to $\mathrm{Al}$ accumulation toxicity. $\mathrm{Al}$ accumulation leads to ROS production and oxidative stress in brain. Increased oxidative stress plays a crucial role in beta-amyloid protein aggregation and deposition. Further, it also forms beta-amyloid plaques. The formation of beta-amyloid plaques stimulates the formation of tangles of tau proteins in the neurons. Excess production of beta-amyloid and irregular accumulation of hyper phosphorylated tau proteins can result in nerve cell apoptosis and NFT formation in the hippocampus, which leading to cell death and neurodegenerative diseases.

At present, chelation is the only possible therapy for mitigating Al toxicity. EDTA, Chlorogenic acid and GSH have been used as chelating agent. However most of these agents are non-specific and chelates other biologically fundamental cations, like magnesium(II), zinc(II) and, above all, iron(III), leading to imbalance in the body. Medicinal plants have emerged as potential alternative for the mitigation of $\mathrm{Al}$ toxicity owing to their multiple mechanism of actions. The recent researches have showed that Jasonia candicans, Jasonia montana, Curculigo orchioides, Withania somnifera (Ashwagandha), Crocus sativus, Rosmarinus officinalis, Angelica sinensis, Nigella 
sativa L., Thymus vulgaris, Ficus religiosa, Pongamia pinnata, Juglans regia, Allium sativum, Zataria multiflora, Coriandrum sativum (coriander), Curcuma longa, Ginkgo Biloba, Panax ginseng, Ferula assafoetida, Polygala paniculata, Gastrodia elata, Polygonum cuspidatum, Scutellaria baicalensis, Sparattosperma leucanthum, Pueraria lobate, Opuntia ficus-indica, Galanthus woronowii, Physostigma venenosum, Polygala tenuifolia, Lavandula angustifolia, Chloranthus henryi, Hypericum perforatum, Atractylodes macrocephala, Salvia officinalis L. and Paeoniae alba Radix possess neuro-protective activity by multiple mechanisms. These plant extracts possesses antioxidants and anti-inflammatory activities helping in minimizing oxidative stress related cellular injuries. The phenolics and flavonoids from plants have emerged as chelators of heavy metals in a holistic way of not leading to deficiencies of essential elements from body. The phytochemicals also reduces formation of betaamyloid and tau proteins under $\mathrm{Al}$ accumulation. So, consumption of medicinal plant products may be a good alternative for preventing $\mathrm{Al}$ toxicity in risk populations.

As the use of herbal medicines is increasing worldwide, the quality of medicinal plant raw material has become a major concern. Some studies have indicated high level of heavy metals in medicinal plants. Medicinal plants growing in contaminated soil and water are likely to accumulate these heavy metals. It is therefore proposed that medicinal plants for the formulation of herbal medicines should be extracted from natural habitats which are free from contamination. It is also recommended that medicinal plant raw materials should be tested for the presence of heavy metals prior to use.

\section{Conflict of Interest}

None to declare.

\section{References}

1. Riihimäki V, Aitio A. Occupational exposure to aluminum and its biomonitoring in perspective. Critical Reviews in Toxicology. 2012;42(10):827-853. https://doi.org/10.3109/ 10408444.2012.725027. PMid:23013241

2. Nie J. Neurotoxicity of Aluminum. 1st ed. Singapore: Springer Nature Singapore Pte Ltd; c2018. Chapter 6, Exposure to Aluminum in Daily Life and Alzheimer's Disease; p. 99-111. https://doi.org/10.1007/978-981-131370-7_6. PMid:30315451
3. Peters S, Reid A, Fritschi L, Klerk NDe, Musk AWB. Longterm effects of aluminium dust inhalation. Occupational and Environmental Medicine. 2013; 70(12):864-868. https:// doi.org/10.1136/oemed-2013-101487. PMid:24142983

4. Bondy SC. Low levels of aluminum can lead to behavioral and morphological changes associated with Alzheimer's disease and age-related neurodegeneration. NeuroToxicology. 2016;52(1):222-229. https://doi. org/10.1016/j.neuro.2015.12.002. PMid:26687397

5. Crisponi G, Fanni D, Gerosa C, Nemolato S, Nurchi VM, Crespo-alonso M, et al. The meaning of aluminium exposure on human health and aluminium-related diseases. BioMol Concepts. 2013; 4(1):77-87. https://doi. org/10.1515/bmc-2012-0045. PMid:25436567

6. Li X, Zhang L, Zhu Y, Li Y. Dynamic analysis of exposure to aluminum and an acidic condition on bone formation in young growing rats. Environmental Toxicology and Pharmacology. 2011; 31(2):295-301. https://doi. org/10.1016/j.etap.2010.11.007. PMid:21787697

7. Tietz T, Lenzner A, Kolbaum AE, Zellmer S, Riebeling C, Gurtler R, et al. Aggregated aluminium exposure: risk assessment for the general population. Archives of Toxicology. 2019; 93(12):3503-3521. https://doi. org/10.1007/s00204-019-02599-z. PMid:31659427

8. Chappard D, Bizot P, Mabilleau G, Hubert L. Aluminum and bone: Review of new clinical circumstances associated with $\mathrm{Al}^{3+}$ deposition in the calcified matrix of bone. Morphologie. 2016; 100(329):95-105. https://doi. org/10.1016/j.morpho.2015.12.001. PMid:26762722

9. Mahor G, Ali SA. An update on the role of medicinal plants in amelioration of aluminium toxicity. Bioscience Biotechnology Research Communications. 2015; 8(2):175188.

10. Klein JP, Mold M, Mery L, Cottier M, Exley C. Aluminum content of human semen: Implications for semen quality. Reproductive Toxicology. 2014; 50(8):43-48. https://doi. org/10.1016/j.reprotox.2014.10.001. PMid:25461904

11. Krewski D, Yokel RA, Nieboer E, Borchelt D, Cohen J, Harry J, et al. Human health risk assessment for aluminium, aluminium oxide, and aluminium hydroxide. Journal of Toxicology and Environmental Health, Part B. 2007; 10:1-269. https://doi.org/10.1080/10937400701597766 PMid:18085482 PMCid:PMC2782734

12. Esparza JL, Gómez M, Domingo JL. Role of melatonin in aluminum-related neurodegenerative disorders: A review. Biological Trace Element Research. 2019; 188(1):60-67. https://doi.org/10.1007/s12011-018-1372-4. PMid:29732485

13. Yokel RA, McNamara PJ. Aluminium toxicokinetics: An updated mini review. Pharmacology \& Toxicology. 2001; 
88(4):159-167. https://doi.org/10.1034/j.1600-0773.2001. d01-98.x. PMid:11322172

14. Exley C. Human exposure to aluminium. Environmental Science Processes \& Impacts. 2013; 15(10):1807-1816. https://doi.org/10.1039/C3EM00374D. PMid:23982047

15. Panossian A, Seo E, Efferth T. Effects of anti-inflammatory and adaptogenic herbal extracts on gene expression of eicosanoids signaling pathways in isolated brain cells. Phytomedicine. 2019; 60(7):1-12. https://doi.org/10.1016/j. phymed.2019.152881. PMid:30987861

16. Kaneko N, Sugioka T, Sakurai H. Aluminum compounds enhance lipid peroxidation in liposomes: Insight into cellular damage caused by oxidative stress. Journal of Inorganic Biochemistry. 2007; 101(6):967-975. https://doi. org/10.1016/j.jinorgbio.2007.03.005. PMid:17467804

17. Bondy SC. The neurotoxicity of environmental aluminum is still an issue. Neurotoxicology. 2010; 31(5):575-581. https://doi.org/10.1016/j.neuro.2010.05.009. PMid:205537 58 PMCid:PMC2946821

18. Liu Z, Zhou T, Ziegler AC, Dimitrion P, Zuo L. Oxidative stress in neurodegenerative diseases: From molecular mechanisms to clinical applications. Oxidative Medicine and Cellular Longevity. 2017; 2017(7):1-11. https://doi.org/10.1155/2017/2525967

19. Patten DA, Germain M, Kelly MA, Slack RS. Reactive oxygen species: Stuck in the middle of neurodegeneration. Journal of Alzheimer's Disease. 2010; 20(S2):S357-S367. https://doi.org/10.3233/JAD-2010-100498.PMid:20421690

20. Go'mez M, Esparza JL, Nogue's MR, Giralt M, Cabre' M, Domingo JL. Pro-oxidant activity of aluminum in the rat hippocampus: Gene expression of antioxidant enzymes after melatonin administration. Free Radical Biology \& Medicine. 2005; 38(1):104-111. https://doi.org/10.1016/j.freeradbiomed.2004.10.009. PMid:15589378

21. Garcia T, Esparza JL, Nogue's MR, Romeu M, Domingo JL, Go'mez M. Oxidative stress status and RNA expression in hippocampus of an animal model of Alzheimer's disease after chronic exposure to aluminum. Hippocampus. 2010; 20(1):218-225. https://doi.org/10.1002/hipo.20612. PMid:19405147

22. Olmos G, Lladó J. Tumor necrosis factor alpha: A link between neuroinflammation and excito toxicity. Mediators of Inflammation. 2014; 2014:1-13. https://doi.org/10.1155/2014/861231 PMid:24966471. PMCid:PMC4055424

23. Danbolt NC. Glutamate uptake. Progress in Neurobiology. 2001; 65(1):1-105. https://doi.org/10.1016/S0301-0082(00)00067-8

24. Rainey-Smith SR, Andersson DA, Williams RJ, Rattray M. Tumour necrosis factor alpha induces rapid reduction in AMPA receptor-mediated calcium entry in motor neurones by increasing cell surface expression of the GluR2 subunit: Relevance to neurodegeneration. Journal of Neurochemistry. 2010; 113(3):692-703. https://doi. org/10.1111/j.1471-4159.2010.06634.x. PMid:20132465

25. Kim BW, Koppula S, Hong SS, Jeon SB, Kwon JH, Hwang BY, et al. Regulation of microglia activity by glaucocalyxin-a: attenuation of lipopolysaccharide-stimulated neuroinflammation through NF- $\mathrm{B}$ and p38 MAPK signaling pathways. PLOS ONE. 2013; 8(2):1-11. https:// doi.org/10.1371/journal.pone.0055792. PMid:23393601 PMCid:PMC3564949

26. Liu B, Hong JS. Role of microglia in inflammation-mediated neurodegenerative diseases: Mechanisms and strategies for therapeutic intervention. The Journal of Pharmacology and Experimental Therapeutics. 2003; 304(1):1-7. https://doi. org/10.1124/jpet.102.035048

27. Bui TT, Nguyen TH. Natural product for the treatment of Alzheimer's disease. Journal of Basic and Clinical Physiology and Pharmacology. 2017; 28(5):413-423. https://doi.org/10.1515/jbcpp-2016-0147. PMid:28708573

28. Pirşcoveanu DFV, Pirici I, Tudorica V, Balseanu TA, Albu VC, Bondari S, et al. Tau protein in neurodegenerative diseases - A review. Romanian Journal of Morphology and Embryology. 2017; 58(4):1141-1150.

29. Wang Y, Tang XC, Zhang HY. Huperzine A alleviates synaptic deficits and modulates amyloidogenic and nonamyloidogenic pathways in APPswe/PS1dE9 transgenic mice. Journal of Neuroscience Research. 2012; 90(2):508-517. https://doi.org/10.1002/jnr.22775. PMid:22002568

30. Saljooghi AS. Chelation of aluminum by combining deferasirox and deferiprone in rats. Toxicology and Industrial Health. 2012; 28(8):740-745. https://doi. org/10.1177/0748233711422731. PMid:22025507

31. Ferrero ME. Rationale for the successful management of EDTA chelation therapy in human burden by toxic metals. BioMed Research International. 2016; 2016:1-13. https://doi.org/10.1155/2016/8274504. PMid:27896275 PMCid:PMC5118545

32. Fulgenzi A, Ferrero ME. EDTA chelation therapy for the treatment of neurotoxicity. International Journal of Molecular Sciences. 2019; 20(5):1-16.

33. Wang X, Fan X, Yuan S, Jiao W, Liu B, Cao J, et al. Chlorogenic acid protects against aluminium-induced cytotoxicity through chelation and antioxidant actions in primary hippocampal neuronal cells. Food and Function. 2017; 8(8):2924-2934. https://doi.org/10.1039/ C7FO00659D. PMid:28745369

34. Lee M, Cho S, Roh K, Chae J, Park JH, Park J, et al. Glutathione alleviated peripheral neuropathy in oxaliplatin-treated mice by removing aluminum from dorsal root 
ganglia. American Journal of Translational Research. 2017; 9(3):926-939.

35. Pandey S, Sharma V, Chaudhary AK. Chelation therapy and chelating agents of Ayurveda. International Journal of Green Pharmacy. 2016; 10(3):143-150.

36. Elufioye TO, Berida TI, Habtemariam S. Plants-Derived Neuroprotective Agents: Cutting the Cycle of Cell Death through Multiple Mechanisms. Evidence-Based Complementary and Alternative Medicine. 2017; 2017:127. https://doi.org/10.1155/2017/3574012. PMid:28904554 PMCid:PMC5585568

37. Ahmed HH, Booles HF, Khalil WKB, Ashmaoui HMEl, Othman SM. Possible therapeutic role of Jasonia Candicans and Jasonia Montana extracts in the regression of Alzheimer's disease in experimental model. American Journal of Biochemistry and Biotechnology. 2013; 9(2):144-161. https://doi.org/10.3844/ajbbsp.2013.144.161

38. Chitra B, Ramaswamy RS. An overview on the role of Siddha practices in the prevention and management of age related neurodegenerative disorders with special reference to senile dementia. Indo American Journal of Pharmaceutical Research. 2015; 5(4):1510-1521.

39. Mohebbati R, Khazdair MR, Hedayati M. Neuroprotective Effects of medicinal plants and their constituents on different induced neurotoxicity methods: A review. Journal of Reports in Pharmaceutical Sciences. 2017; 6(1):34-50.

40. Huang W, Cheng P, Yu K, Han Y, Song M, Li Y. Hyperforin attenuates aluminum-induced $\mathrm{A} \beta$ production and Tau phosphorylation via regulating Akt/GSK-3 $\beta$ signaling pathway in PC12 cells. Biomedicine \& Pharmacotherapy. 2017; 96(12):1-6. https://doi.org/10.1016/j.biopha.2017.09.114. PMid:28961505

41. Kim J, Park S, Ha H, Moon C, Shin T, Kim J, et al. Opuntia ficus-indica attenuates neuronal injury in in vitro and in vivo models of cerebral ischemia. Journal of Ethnopharmacology. 2006; 104(1-2):257-262. https://doi. org/10.1016/j.jep.2005.09.017. PMid:16243466

42. Gambino G, Allegra M, Sardo P, Attanzio A, Tesoriere L, Livrea MA, et al. Brain distribution and modulation of neuronal excitability by indicaxanthin from Opuntia ficus indica administered at nutritionally-relevant amounts. Frontiers in Aging Neuroscience. 2018; 10(133):1-11. https://doi.org/10.3389/fnagi.2018.00133. PMid:29867444 PMCid:PMC5954040

43. Khazdair MR, Anaeigoudari A, Hashemzehi M, Mohebbati R. Neuroprotective potency of some spice herbs, a literature review. Journal of Traditional and Complementary Medicine. 2019; 9(2):98-105. https://doi.org/10.1016/j. jtcme.2018.01.002. PMid:30963044 PMCid:PMC6435951

44. Kumar GP, Khanum F. Neuroprotective potential of phytochemicals. Pharmacognosy Review. 2012; 6(12):81-90. https://doi.org/10.4103/0973-7847.99898. PMid:23055633 PMCid:PMC3459459

45. Pereira DM, Valentão P, Pereira JA, Andrade PB. Phenolics: From chemistry to biology. Molecules. 2009; 14(6):22022211. https://doi.org/10.3390/molecules 14062202 . PMCid:PMC6254163

46. Symonowicz M, Kolanek M. Flavonoids and their properties to form chelate complexes. Biotechnology and Food Sciences. 2012; 76(1):35-41. 